\title{
Science fiction fantasies
}

I truly am grateful for the scientific and engineering advances that have occurred during my lifetime. Our lives have been improved in ways that our ancestors could only dream about, and materials research has been at the forefront of that progress. However, I've also been a fan of science fiction from my earliest years, and I can't help but wish we had some of the devices and materials that so far exist only on-screen or in books. It's not like I want a flying car like we see in The Jetsons ${ }^{1}$ or The Fifth Element. ${ }^{2}$ It's crazy enough driving through traffic in Los Angeles without worrying about someone coming at me from above or below. However, I do want those suborbital transports (Land of the Giants, ${ }^{3}$ The Unincorporated $\mathrm{Man}^{4}$ ) that would take me from LA to London or LA to New Delhi in 45 minutes rather than the 14-18 hours that the fastest air transport currently takes. All we would need is better materials for the fuselage and for the engines. And a power source. Maybe we'd actually need Star Trek's dilithium crystals to provide the power. ${ }^{5}$ Is that too much to ask?

I also want my own space ship. I would love to be able to explore the solar system and the galaxy. I'm certainly not interested in being in a vessel shot out of a giant cannon as in From the Earth to the Moon, ${ }^{6}$ Jules Verne's 1865 novel. Even if we had super tough materials that could survive such a launch, the human body could never take it. At my age, I'm not even interested in experiencing the normal, powered rocket launch that is common today. The human race has launched hundreds of manned and unmanned spacecraft in this fashion, and the materials science associated with reliable launch is well known. Nonetheless, the inertial stress on the human body is significant. No, I want a spacecraft that can take me to orbit in a gentle fashion, either through a novel propulsion system that allows powered flight to orbit at low acceleration, inertial dampeners that eliminate the effects of acceleration on mass, ${ }^{5}$ or an antigravity system that would float me gently into space. My spacecraft also has to help me survive the space environment. I cannot be exposed to intolerable levels of radiation. I cannot be exposed directly to vacuum or to the extremes of temperature that one finds in space. The interior environment of the spacecraft must be sufficiently earthlike that I can explore the universe in comfort. Oh, and I'd really like to have a holodeck for recreation (Star Trek: The Next Generation, Voyager, Deep Space Nine). ${ }^{5,7}$

Instantaneous transport across large distances would be even better, but use of matter transporters raises different issues. I am not interested in traveling through either the Star Trek transporter, or use of the star gates (e.g., from Star- gate $S G-1,{ }^{8}$ Stargate Atlantis, ${ }^{9}$ and Stargate Universe ${ }^{10}$ ), which invoke transport from gate to gate through wormholes. ${ }^{11}$ In both cases, the idea of having my matter ripped apart at one location and reconstructed at another location is just too much for me. Maybe I'm just an old fuddy-duddy, but nobody has comprehensively addressed the issue of "self." Is it really you that shows up at the other end of the Stargate wormhole or is it just a really, really good copy (memories and all)? Also, how would one use current technology to ensure that bit errors in the matter stream ${ }^{5}$ did not corrupt the materials in the copy as occurred at a really gross scale in Star Trek: The Motion Picture? The Star Trek writers invoke something called Heisenberg compensators to deal with the uncertainty associated with the subatomic precision needed. ${ }^{12}$

Despite the marvelous sense of advancement evoked by the mere concept of Heisenberg compensators, the various Star Trek series and movies have dealt with numerous transporter malfunctions. Some of these accidents involved issues of phasing of the matter involved, although it's never clear what that means. In the episode "The Next Phase" of Star Trek: The Next Generation, ${ }^{13}$ two of the crew members are trapped in a situation in which they are out of phase with the normal universe. They can pass through 
solid matter, with only the emission of "chronotron" particles as evidence of the passage. The word "chronotron" evokes the idea of time, as if the matter involved is out of phase in time in some way. Curiously, this only seems to involve lateral motion, because the affected crew members and their Romulan adversary can stand on floors without any problem. In their phased state, the two crew members can see and hear other crew members who cannot see or hear them. The asymmetries associated with matter and materials as well as their interaction (or lack thereof) with fields in these science fiction concepts is fascinating. This episode and others suggest consciousness and thus perpetuation of self throughout the transport process. Nonetheless, I would need to be convinced of the transmission of self, not just the transmission of matter, before I would risk teleportation of this sort.

The stargates in the various Stargate television series are formed from a superconductor made from a material called "naquadah," which must be very durable to support the event horizon associated with one end of a stable wormhole. ${ }^{14}$ Naquadah is indicated to be a "quartzite" material not found on earth. Gates in the various series have also survived the impact of meteors and crashes of starships.

An earlier version of a gate (Star Gate $^{15}$ by Andre Norton) connected alternate realities, which made for an interesting story. If I could transport safely into an alternate reality in which I was the beloved emperor of all humankind, that might be appealing. Of course, that guy would have to vanish as soon as I arrived. But with my luck, I'd run into some many-worlds version of entropy that ensured that travel could only occur to alternate universes in which your personal situation was worse.

If I'm going to use a matter transporter, it has to be one that is like opening a door from one room to another. Only the rooms are separated by miles or by light-years. The complexities associated with matching velocities on the two sides of the door are mind-boggling, but if it could be done, I might be persuaded to try it.

A Star Trek staple that I really do want is one of the replicators. ${ }^{5,16}$ To be able to come home at the end of a long work day and just say, "Hand-carved

roast turkey, Mom's cornbread stuffing and mashed potatoes, Grandma's apple pie with homemade ice cream." And have that delivered to me in no time at all by assembly of complex molecules from subatomic particles. Wow! We now have three-dimensional printers that can produce objects from material feedstocks. The printers are fairly sophisticated and have been used to produce items as complex as a titanium implant for replacement of a human lower jawbone. ${ }^{17}$ But, it's just not the same as being able to create almost any material directly from subatomic particles almost instantaneously.

Both science fiction and science fantasy invoke a wide range of materials. For further reading, I recommend the entry in Wikipedia listed in Reference 18. For more information about the materials and technologies used in the science fiction universe of the Stargate series, see Reference 19

I also strongly recommend reading science fiction and fantasy. Many of the stories have inspired real advances in science and engineering.

Steve Moss

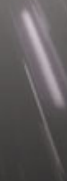

\section{References}

1. The Jetsons, animated sitcom produced by Hanna-Barbera; http://en.wikipedia.org/wiki/The Jetsons

2. The Fifth Element, movie (1997); http://en.wikipedia.org/wiki/The_Fifth_Element.

3. Land of the Giants, television program, ABC (1968-1970);

http://en.wikipedia.org/wiki/Land_of_the_Giants.

4. Dani Kollin and Eytan Kollin, The Unincorporated Man (TOR Books, 2009)

5. Lawrence Krauss, The Physics of Star Trek (Basic Books, 2007)

6. Jules Verne, From the Earth to the Moon (1865).

7. http://en.wikipedia.org/wiki/Holodeck.

8. Stargate SG-1, television series (1997-2007); http://en.wikipedia.org/wiki/Stargate_SG-1.

9. Stargate Atlantis, television series (2004-2009); http://en.wikipedia.org/wiki/Stargate_Atlantis.

10. Stargate Universe, television series (2009-2011); http://en.wikipedia.org/wiki/Stargate_Universe.

11. Enrico Rodrigo, The Physics of Stargates: Parallel Universes, Time Travel,

and the Enigma of Wormhole Physics (Eridanus Press, 2010).

12. http://en.wikipedia.org/wiki/Transporter_(Star_Trek).

13. http://en.wikipedia.org/wiki/The_Next_Phase.

14. http://stargate.wikia.com/wiki/Stargate; or

http://www.stargate-sg1-solutions.com/wiki/Stargate.

15. Andre Norton, Star Gate (Harcourt, 1958)

16. http://en.wikipedia.org/wiki/Replicator_Star Trek)

17. http://abcnews.go.com/blogs/health/2012/02/07/woman-83-has-worlds-first-lower-jaw-replacement-in-3d/

18. http://en.wikipedia.org/wiki/Materials science in science fiction.

19. http://en.wikipedia.org/wiki/Technology_in_Stargate.

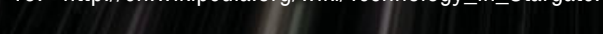

